Ankara Ecz. Fak. Mec.

13. 193 (1983)
J. Fac. Pharm Ankara

13193 (1983)

\title{
İç Anadolu Bölgesi'nde Ateş Düşürücü Olarak Kullanilan Halk İlaçları
}

\author{
Antipyretic Folk Remedies Used in Central Anatolia Region \\ Mekin TANKER* \\ Eriş ASİL** \\ Sevgi ŞAR**

\section{GİRİŞ}

Halkın olanakları bulunmadığı zaman veya başka nedenlerle hekime başvurmayınca veya başvurmak istemeyince hastalıklarını teşhis ve tedavi amacıyla uyguladı̆̆ işlemlerin tümüne "Halk Hekimliği" denilmektedir $(3,10)$. Halk Hekimliği uygulaması içinde önemli bir yeri olan halk ilaçlarının ülkemizde oldukça yaygın olarak kullanıldı̆̆ı bilinmektedir.

Halk hekimliğinde "Hastalık" deyimi, bireyin sağlık durumundaki bozuklukların yanısıra, kısırlıktan nazar değmesi gibi insanlardan gelebilecek kötü etkilere ve cin, peri gibi doğaüstü varlıkların neden olabilecekleri türlü sakatlıklara kadar birçok kavramı içermektedir. Bu nedenle halk ilaçları 3 gruba ayrılabilir $(3,10)$.

1. Büyü niteliği taşıyan halk ilaçları

2. Hem büyü, hem gerçekçi nitelik taşıyan halk ilaçları

3. Gerçekçi nitelik taşıyan halk ilaçları.

Bu çalışmada İç Anadolu Bölgesi'nde ateş düşürücü olarak kullanılan halk ilaçları ele alınmış ve genellikle gerçekçi nitelik taşıyanlar

Redaksiyona verildiği tarih: 5 Temmuz 1983

* Farmakognozi Anabilim Dalı, Eczacılık Fakültesi, Ankara Üniversitesi.

** Eczacılık Tarih ve İşletmeciliği Bilim Dalı, Eczacılık Fakültesi, Ankara Üniversitesi. 
üzerinde bilimsel inceleme yapılmıştır. Halkımızın ilaçla tedavinin yanısıra manevi güçlerden de yarar göreceği inancına rağmen birinci ve ikinci gruba giren ilaçlar bu çalışma kapsamına alınmamıştır.

\section{MATERYAL ve YÖNTEM}

Çalışmamızın materyalini İç Anadolu Bölgesi'nde oturan halktan topladı̆̆ımız bilgiler oluşturmaktadır.

$\mathrm{Bu}$ bilgileri toplamak için kullanılan yöntem ise Sahada Folklor Derleme Yöntemlerinden biri olan "Oral Tradition" tekniğidir (15).

Tekniğin uygulanması amacıyla geliştirilen ve aşağıda bir örneği görülen Kayıt Formları kullanılmıştır*.

\begin{tabular}{|l|}
\hline \multicolumn{2}{|c|}{ A. Ü. Eczacılık Fakültesi } \\
Eczacılık Tarihi ve İşletmeciliği \\
Bilim Dalı \\
HALK İLAÇLARI ARAŞTIRMA FORMU \\
Yöre (İl, ilçe, köy) \\
Kaynak kişi (Ad,, cinsiyeti, yaşı) \\
Kullanıldığı hastalık \\
İlacın terkibi \\
Kullanılış şekli \\
Yöresel adı \\
İlacın hikayesi \\
\hline
\end{tabular}

İç Anadolu Bölgesi'nde bulunan 10 ile bağlı 60 ilçe ve 370 köy bu araştırma için gezilmiş, yaklaşık 3000 kişi ile görüşülmüştür.

Toplanan materyalin değerlendirilmesi için Bölge'de kullanılan halk ilaçları, hastalıklara göre sınıflandırılarak kodlanmıştır. İncelemelerimiz çeşitli tıp ve eczacılık kitapları ile dergi ve makalelerden yararlanarak, halk ilaçlarının, genel olarak halk hekimliğinin günümüz modern tıp ve eczacılı̆̆ı ile karşılaştırılması şeklinde olmuştur. Toplanan materyal üzerinde etnolojik bir değerlendirme de yapılmaya çalışılmıştır.

* Araştırma ile ilgili formlar A. Ü. Eczacılık Tarihi ve İşletmeciliği Bilim Dalı Arşivi'nde saklanmaktadır. 


\section{İç Anadolu Bölgesi'nde Ateş Düşürücü Olarak Kullanı- lan Halk İlaçları.}

1. Bir limonun tepe kısmı kesilir, içi oyulur, ham afyon ile doldurularak külde pişirilir, pomad şeklinde vücuda sürülür.

2. Bir baş sarımsak, bir miktar alkolde bir ay bekletilir, bu sıvıdan bir bardak suya birkaç damla ilave edilerek hastaya içirilir.

3. Bir bardak soğuk suya bir fincan sirke karıştırılır, vücut bu karışımla ovulur.

4. Sarımsaklı yoğurt vücuda sürülür.

5. Bir tutam papatya çiçeği bir bardak sıcak suda 15 dakika bekletilir, süzülür ve çay gibi içilir.

6. Bir miktar kiraz ağacı kabuğu suda kaynatılır, süzülür ve sabah akşam birer fincan içilir.

7. Bir limonun tepe kısmı kesilir, içi oyularak tuz doldurulur. Külde pişirildikten sonra 1lık olarak vücut ovulur.

8. İki çorba kaşı̆̆ı kınaya bulamaç haline gelinceye kadar sirke ilave edilip karıştırılır, ateşlenen kişinin ayak tabanlarına sürülür.

9. Bir aspirin tableti bir fincan rakı içinde ezilip ateşi yükselen çocukların alın ve bileklerine sürülür.

10. Bir miktar akasya çiçeği yapraklarıyla beraber suda kaynatılır, elde edilen sivi ile banyo yapılır.

11. Bir bardak sıcak suya bir tutam ufalanmıs pelin otu atılır. 15 dakika bekletilir, süzülür, süzüntü çay gibi içilir.

12. Bir avuç gelincik çiçeği suda kaynatılır, süzülür, süzüntüden günde bir çay bardağı içilir.

13. Birer avuç papatya çiçeği ve arpa suda kaynatılır, süzülür, süzüntüden her yemekten sonra birer bardak içilir.

14. Bir tutam karanfil çiçeği bir bardak sıcak suda 10 dakika bekletilir, süzülür, süzüntü çay gibi içilir.

15. Bir bă maydanoz suda kaynatılıp süzülür, süzüntüden günde bir fincan içilir. 
İç Anadolu Bölgesin'de Ateş Düşürücü Olarak Kullanilan Halk İlaçlarının İçerdiği Drogların Değerlendirilmesi.

\section{Afyon, O p i u m}

Bölge'de kültürü yapılan Papaver somniferum (Papaveraceae) varyetelerinin olgunlaşmaya başlayan meyvalarının çizilmesiyle akıtılan lateksin havada kurutulmuş şeklidir. Bileşiminde morfin, kodein, tebain, papaverin, laudanin, narkotin ve narsein alkaloitleri, şeker, reçine, kauçuk, yă̆, mum, müsilaj ve bazı asitler taşımaktadır (11, $24,28,32)$. Opiumun içerdiği morfin ve narseinden dolayı kuvvetli analjezik ve narkotik, kodeinden dolayı öksürük kesici, papaverin ve narkotinden dolayı çizgisiz kas spazmalarını çözücü etkileri bilinmektedir $(32,34,35)$.

Afyon çok eski zamandan beri ilaç ve keyif verici madde olarak kullanılmıştır. Ebers Papirus'da kayıtlı olan drog, Eski Mısır'da baş ve kulak ağrıları için (4, 30), Eski Çin ve Hind'de narkotik olarak kullanılmaktaydı (21). D I O S C O R I D ES afyonu, bugünkü anlamda ilaç olarak kullanan ilk hekim-eczacıdır (16). CELSUS ve GALEN'in hazırladığı birçok reçeteye giren droğu İ BNİ-SİNA öksürük kesici olarak kullanmıştır $(18,23)$. Anadolu Selçukluları ve Osmanlılar Devirlerinde $(1,2)$ ağrı kesici olarak kullanılan drog ilk kodekslerimizden Düstur al-Edviye'de (19) ve 1930, 1940, 1948 ve 1974 Türk Kodekslerinde de kayitlıdır.

Droğun İç Anadolu Bölgesi halkı arasında kullanılışı, içerdiği etken maddelerin etkilerine uygunluk göstermektedir.

\section{Akasya Çiçeği ve Yapră̆ı, Flores Robiniae, Folia Robiniae}

Bölge'de kültürü yapılan Robinia pseudoacacia (Fabaceae) bitkisinin çiçek ve yapraklarıdır. Çiçeklerin bileşiminde robinosid flavanozidi, mum, asparagin ve uçucu yağ; yaprakların bileşiminde ise tanen, indican ve acaciin isimli glikozid bulunmaktadır $(6,8)$. Yapraklar ve dal kabukları yüksek dozlarda zehirli olup yapraklarından hazırlanan infüzyon dahilen sindirim sistemi hastalıklarında kullanılmıştır (6). Diüretik etkisi de bilinmektedir (8).

Droğun halk arasında kullanıldı̆̆ ateş düşürücü olarak kullanılışına literatürde rastlanmamıştır. Bu ne- 
denle bilinen yapı ve etkileri dikkate alındığında bu tarzda kullanıldı̆̆ında halkın elde ettiği sonuç şüpheli olarak görülmektedir.

\section{Alkol, Alcohol}

İç Anadolu Bölgesi Halk Hekimliğinde bazı alkollü içkiler de ilaç olarak kullanılmaktadır. Alkol (etanol), en eski fermantasyon ürünlerinden biridir. Alkol distilasyonu ilk defa XIII. yüzyılın ikinci yarısında yapılmış ve "aqua vini" veya "aqua vital" adı ile kuvvet verici ve ömür uzatıcı olarak kullanılmıştır (32). Etanol, santral sinir sistemi depresörüdür ve bu nedenle genel anestezi yapar; ayrıca antipiretik etkisi de bilinmektedir (32). \% 70 lik etanol çözeltisinin haricen antiseptik olarak, \% 50 lik çözeltisinin astrenjan ve nem alıcı losyon hazırlanmasında, \% 25 lik çözeltilerinin ise deriyi soğutmak ve ateş düşürücü olarak kullanıldığı kaydedilmektedir (32).

Droğun bölge halkı arasındaki kullanılışı bilinen etkilerine uygunluk göstermektedir.

\section{Arpa, Fructus Hordel Decorticati}

İç Anadolu Bölgesi'nde kültürü yapılan Hordeum sativum (Graminae) bitkisinin tohumlarıdır. Arpa, karbohidrat bakımından zengin olup nişasta, şeker, enzimler, hordein ve hordenin alkaloitlerini içermektedir. $(5,12,32)$. Drog, demülsan, emoliyan etkili olup ayrıca ekmek üretiminde de kullanılır (12). Bira sanayiinde kullanıldığ 1 ve hordenin alkaloitinden dolayı antidiyaretik etkili olduğu kaydedilmektedir (32).

Droğun halk arasında kullanılış şekline literatürde rastlanmamıştır. Bu nedenle arpanın bilinen yapı ve etkileri gözönüne alındı̆̆ zaman halkın elde ettiği sonuç şüpheli olarak görülmektedir.

\section{Gelincik Çiçeği, Flos Rhoeados}

İç Anadolu Bölgesi'nde doğal olarak yetişen Papaver rhoeas ( $\mathrm{Pa}$ paveraceae) bitkisinin petalleridir. Droğun bileşiminde zamk, müsilaj, şeker, bir antosiyanozid derivesi olan siyanidol ve roadin alkaloidi bulunmaktadır $(5,7,8,9,12,35)$. Taşıdı̆̆ 1 roadinden dolayı öksürük sedatifi, müsilajdan dolayı göğüs yumuşatıcı ve renk maddelerinden dolayı da boyayıcı olarak etki yaptığı bilinmektedir $(5,7$, 
8, 12, 20, 27, 32, 35). Gelincik çiçeği 1930, 1940 ve 1948 Türk Kodekslerinde de kayıtlıdır. Narkotik ve sudorifik etkileri olduğu da bildirilmektedir (9).

Çok eskiden beri tanınmakta olan droğu, D I O S C O R I D E S (16), antienflamatuvar, sedatif ve ekspektoran olarak kaydetmektedir. Osmanlılar döneminde göğüs yumuşatıcı olarak çok aranırdı $(1,13)$.

Droğun bilinen yapı ve etkileri gözönüne alındığı zaman halkın elde ettiği sonuç şüpheli olmakla beraber sudorifik etkiye bağlı olarak ateş düşürmesi de beklenebilir.

\section{Karanfil Çiçeği, Caryophyllus}

Bir tropikal bölge bitkisi olan Eugenia caryophyllus (Myrtaceae) bitkisinin kurutulmuş çiçek goncalarıdır. Bileşiminde uçucu yă̆, tanen ve caryophyllin bulunmaktadır $(7,20)$. Bileşimindeki uçucu yağın taşıdı̆̆ı öjenolden dolayı antiseptik ve anajlezik olarak diş hekimliğinde kullanılmakta ayrıca midevi ve karminatif etkileri de bilinmektedir $(7,17,25,32)$.

Osmanlılar ve Anadolu Selçukluları devirlerinde (1, 2) afrodizyak olarak kullanılan drog, ilk kodekslerimizden Düstur al-Edviye'de ve 1930, 1940 ve 1948 Türk Kodekslerinde de kayıtlıdır (19). Eski Mısır Çarşısı'nda çok satılan bir drog olduğu da bilinmektedir (13).

Droğun bilinen yapı ve etkileri gözönüne alındığında halkın kullandığı alanda yararlı olacağı şüpheli görülmektedir.

\section{Kına Yaprăğ, Folium Lavvsoniae}

Drog, ülkemizde yetişmeyen Lalvsonia inermis (Lythraceae) bitkisinin kurutulup toz edilmiş yapraklarıdır. Yapısında reçineli bileşikler, tanen ve bir boya maddesi olan lawson taşır (7, 33). BAYTOP (7), yapraklardan hazırlanan tentürün kalp üzerinde yatıştırıcı bir etkisi olduğunu bildirmektedir. Lawsondan dolayı kozmetik olarak kullanılmakta, tanenden dolayı deri hastalıklarında büzücü bir etki yapmaktadır $(7,33)$. Droğun antidiyaretik ve diüretik etkileri de bilinmektedir (8).

Eski Mısır'da yazılmış tıbbi tabletlerde adına rastlanan drog Anadolu Selçukluları ve Osmanlılar devirlerinde boya meddesi olarak kullanılmaktayd 1 (1, 2, 4). 
Droğun yapısı ve bilinen etkileri gözönüne alındı̆̆ında halkın kullandığı alanda yararlı olacağı şüpheli görülmektedir.

\section{Kiraz A ğacı Kabuğu}

Bölge'de kültürü yapılan Prunus avlum (Rosaceae) bitkisinin ağaç kabuklarıdır. Bitki kabuğunun ateş düşürücü etkisine literatürde rastlanmamıştır. Bitki kabuklarının kimyasal yapısı hakkında da bir bilgimiz bulunmadığ 1 için halkın kullandı̆̆ sağlamayacağı konusunda karar verilememiştir.

\section{Limon Kabuğu, Pericarpium Citri}

Akdeniz ve Ege Bölgelerinde kültürü yapılan Citrus medica var. limonum (Rutaceae) bitkisinin olgun meyvalarının kabuklarıdır. Bileşiminde uçucu yağ, G vitamini, hesperidin, acı maddeler, müsilaj, kalsiyum oksalat ve pektin bulunmaktadır (6, 7, 20, 27). Eskiden antiseptik ve antiskorbütik olarak çok kullanılan droğun iştah açıcı, midevi ve koku verici etkileri bilinmektedir $(6,7,12,20)$.

İ B İ SİNA'nın da kaydettiği drog (18), Osmanlılar devrinde midevi olarak kullanılmıştır (1). Eski Mısır Çarşısı'nda midevi olarak çok aranan drog (13), Düstur al-Edviye'de (19), 1930, 1940 ve 1948 Türk Kodekslerinde de kayıtlıdır.

Droğun ateş dürücü olarak kullanıldığına dair literatürde herhangi bir bilgiye rastlanmamıştır.

\section{Maydanoz, Herba Petroselini}

Bölgede kültürü yapılan Petroselinum sativum (Umbelliferae) bitkisidir. Bitkinin köklerinde uçucu yağ, şeker, müsilaj, apiin; yapraklarında ise A, C, K vitaminleri bulunmaktadır (6, 9). Droğun bileşimindeki uçucu yağın idrar söktürücü, midevi, tansiyon yükseltici, iştah açıcı ve adet söktürücü etkileri bilinmektedir $(6,8,9,12,32)$. Yaprakların lapa halinde eskiden iltihaplı yaraların tedavisinde kullanıldı̆̆ 1 kaydedilmektedir (6).

H IP POCRATES'inidrar söktürücü olarak tavsiye ettiği drog (4), ilk kodekslerimizden Düstur al-Edviye'de de kayıtlıdır (19).

Droğun literatürde ateş düşürücü olarak kullanıldı̆̆ına rastlanmamıştır. 


\section{Papatya Çiçeği, Flores Chamomillae}

Bölge'de doğal olarak yetişen Matricaria chamomilla (Compositae) bitkisinin kapitulumlarıdır. Bileşiminde acı madde, kolin, tanen ve uçucu yağ bulunmaktadır $(6,20,28,33)$. Uçucu yağ ise bazı seskiterpenik maddeler, ya $\breve{g}$ asitleri, asetik ve salisilik asitler ve bunların esterleri, parafin ve kamazulen taşır $(6,33)$. Kamazulenden ileri gelen antienflamatuvar etkisi olan drog, ateş düşürücü, spazm çözücü, yatıştırıcı, terletici, bağırsak gazlarını giderici ve ağrı kesici olarak infüzyon halinde; dişeti ve bademcik iltihaplarına karşı ve saç boyası olarak dekoksiyon halinde kullanılmıştır $(6,8,12,17,20,28,33)$.

Drog ilk kodekslerimizden Düstur al-Edviye'de ve 1930, 1940 ve 1948 Türk Kodekslerinde kayıtlı olup, Osmanlı ve Anadolu Selçukluları dönemlerinde karın ağrılarına karşı kullanılırdı $(1,2)$.

Drog bölge halkı tarafından yapısı ve bilinen etkilerine uygun olarak kullanılmaktadir.

\section{Pelinotu, Herba Absinthii}

Bölge'de doğal olarak yetişen Artemisia absinthium (Compositae) bitkisinin kurutulmuş yaprak ve çiçekli dallarıdır. Bileşiminde uçucu yă̆, tanen, reçine ve absintin bulunur (6, 7, 20, 33). Drog yapısındaki absintinden dolayı iştah açıcı olarak kullanılmıştır $(8,12,17$, 33, 34). Bitkinin taşıdı̆̆ zehirli maddeler olup, düşük dozlarda titreme, hallüsinasyon bitkinlik ve uyuşuklukla kendini gösteren bir zehirlenme tablosu oluşturur (33). Droğun kurt düşürücü, adet söktürücü, çocuk düşürücü etkileri varsa da bu etkilerin meydana gelmesi için yüksek dozda alınması gerektiğinden zehirlenmelere yol açabileceği nedeniyle bugün ilaç olarak kullanılmamaktadır $(6,7,8,12,25,27)$.

Pelinotu çok eski devirlerden beri tanınan bir bitkidir. Eski Mezopotamya'da öksürük kesici (13), Eski Çin'de kurt düşürücü olarak kullanılmıştır (22). H I P POCRATES $(4,6)$, bitkiyi sarılık tedavisinde tavsiye eder. Ebers Papirüs (4) ve DIOSCORIDES (16) de de kayıtlı olan droğu AL-Bİ R UN î (18) baş ağrılarına karşı kullanmıştır. İlk kodekslerimizden Düstur al-Edviye'de (19) kayıtlı olup eski Mısır Çarşısında sıtmaya karşı ve iştah açıcı olarak satılırdı (13). 
Literatürde bölge halkının kullandığı şekilde ateş düşürücü olarak kullanılışına rastlanmamıştır. Bu nedenle ateş düşürücü olarak yarar sağlayacağı şüpheli görülmektedir.

\section{Sarımsak, Bulbus Allii}

Bölge'de kültürü yapılan Allium sativum (Liliaceae) bitkisinin soğanlarıdır. Bileşiminde şeker, fermentler, A, B, C, P vitaminleri, uçucu yağ ve allicin adlı bir antibiyotik bulunmaktadır $(6,20)$. Dahilen tansiyon düşürücü, diüretik, vermifüj, antiseptik, ekspektoran etkileri bilinmektedir $(6,8,12,17,20,28)$. Allicin'in ise bakterisid etkisi vardir $(31)$.

Eski Mısır'da ilaç olarak kullanıldığı bilinen droğa (29), M.Ö. 7-8. yüzyıllara ait tıbbi tabletlerde de rastlanmıştır (4). DIOSCORIDES'in (16) birçok hastalığa karşı tavsiye ettiği drog, Anadolu Selçukluları ve Osmanlılar devirlerinde kellik, saçkıran ve uyuza karŞ1 kullanılmıştır $(1,2)$.

Droğun ateş düşürücü olarak kullanılışına literatürde rastlanmamıştır.

\section{Sirke, Acetum}

Sirke, \% 6 asetik asit içeren bir fermantasyon ürünüdür (32). Şarap sirkesi tartarik asit, glikoz sirkesi dekstrin, odun sirkesi ise furfurol ihtiva etmektedir (17).

Ebers Papirus'da kayıtlı olan drog, Antik Misır'da farmasötik şekillerin hazırlanmasında kullanılmıştır (4, 30). GALEN'in kan durdurucu olarak kaydettiği dorg (4), veteriner folklorunda da ayrı amaçla kullanılmaktadır (14).

Droğun ateş düşürücü sistemik bir etkisine literatürde rastlanmamıştır.

\section{Tuz, Natrii Chloridum}

Tuz çok eski devirlerden beri bilinen ve ilaç olarak kullanılan bir maddedir. Ninova'da bulunan M.Ö. 7. yüzyıla ait tabletlerde (4) tuza rastlanmaktadır. D I O S C O R I D E S (16) tarafından da ilaç olarak kaydedilmektedir. Anadolu Selçukluları (2) tuzu ilaç olarak kullan- 
mışlardır. İlk kodekslerimizden Düstur al-Edviye'dc (19) ve 1930, 1940, 1948 ve 1974 Türk Kodekslerinde de kayıtlıdır. XVI. yüzyıla ait Türkçe tıp yazmalarında drogdan söz edilmekte, XVII. yüzyıl eserlerinde uyuz ve kaşıntılı deri hastalıklarında ve dişeti kanamalarinda tavsiye edilmektedir (13).

Bugün tıpta \% 0.9 luk steril solüsyonlar halinde kullanılır (17). Sürgüt ve kusturucu etkileri bilindiği gibi çocuklar için burun damlası olarak da verilir (17).

Tuzun ateş düşürücü etkisine literatürde rastlanmamıştır.

\section{Yoğurt}

Yoğurt bir süt ürünüdür (26). Süt, süt şekeri, yağ, azotlu ve mineral maddeler, vitaminler, enzimler pigmentler, karbondioksit, azot, oksijen gazları, biyolojik elemanlar ve sütün mikroflorasından oluşur (26).

Önemli bir besin maddesi olan sütün ateş düşürücü etkisine literatürde rastlanmamıştır.

\section{SONUÇ ve TARTIŞMA}

Bu araştırmada İç Anadolu Bölgesi'nde halk arasında ateş düşürücü olarak 15 ilaç terkibinin kullanıldı̆̆ saptanmıştır. Bu ilaçlar 17 drogdan yapılmaktadır. Ateş düşürücü halk ilaçları Bölge'de kullanıldı̆̆ı saptanan tüm halk ilaçlarının (926 adet) \% 1.62 sini oluşturmaktadir.

\section{Bu 17 drogdan:}

15 tanesi bitkisel

1 tanesi hayvansal

1 tanesi mineral kaynaklıdır

15 bitkisel kaynaklı drog 13 bitkiden elde edilmektedir. Bunlardan:

3 tanesi bölgede doğal olarak yetişmekte

7 tanesinin bölgede kültürü yapılmakta 
1 tanesi bölgede yetişmemekte

2 tanesi ise ülkemizde yetişmemektedir.

17 drogdan:

4 tanesi günümüzde de ilaç olarak kullanılmakta

13 tanesi ise ilaç olarak kullanılmamaktadır.

Bugün ilaç olarak kullanılmayan bu 13 droğun 5 tanesinden çeşitli etken maddeler elde edilmektedir.

Halkın ilaç olarak kullandı̆̆ 17 drogdan:

3 tanesi bilinen etkilerine uygun olarak kullanılmakta

14 tanesinin ise kimyasal yapıları dikkate alındığında ateş düşürücü etki göstermesi şüpheli görülmektedir.

$\mathrm{Bu}$ çalışmada saptanan drogların hemen hepsinin çok eski devirlerden beri ilaç olarak bilinen ve klasik yazarlarca kaydedilen droglar olduğu görülmektedir.

Araştırmalarımız, yaygın bir uygulama alanı olan halk ilaçlarının yaşamasında en büyük etkenin halkın çoğunlukla kırsal alanda ve kapalı ekonomi içinde yaşaması olduğunu göstermiştir. Ancak, eğitim, haberleşme ve ulaşım olanaklarının artması, geleneksel halk kültürü ile çağdaş kültürün etkileşmesine, halkın bilinçlenerek batıl inançlardan giderek uzaklaşmasına, gelenek ve göreneklerin daha akılcı yönleriyle yaşamasına neden olmaktadır.

\section{ÖZET}

Bu çalışmada İç Anadolu Bölgesi'nde ateş düşürücü olarak kullanılan halk ilaçları incelenmiştir. Sahada Folklor Derleme Yöntemlerinden biri olan Oral Tradition tekniği kullanılarak toplanan materyal değerlendirilmiş, çeşitli istatistik sonuçlar elde edilmiş ve konu tartışılmıştır.

Elde edilen sonuçlara göre bölgede 17 drogdan oluşan 15 ilaç ateş düşürücü olarak kullanılmaktadır. Bu 17 droğun 15'i bitkisel, birer tanesi ise hayvansal ve mineral kaynaklıdır. 17 droğun 4 tanesi günümüzde de ilaç olarak kullanılmakta olup 13 tanesi ise modern tedaviden kaldırılmıştır. Ancak bunların 5'inden çeşitli etken maddeler elde edilmektedir. 


\section{SUMMARY}

In this study, the antipyretic folk remedies which arc used in Central Anatolia Region have been investigated. The materials which arc collected by applying "Oral Tradition Thecnic", one of the Folklore Research Methods in Field, have been evaluated, various statistical results obtained and discussed.

According to the results: Fifteen antipyretic folk remedies which are formed from 17 drugs are used in Central Anatolia Region. Of these, 15 drugs are obtained from plants, 1 drug is obtained from animals and $1 \mathrm{drug}$ is mineral originated. Four of these $17 \mathrm{drugs}$ are still used and 13 drugs are not used as remedy in our times. But, 5 of these are used in extracting various effective substances.

\section{LİTERAT ÜR}

1- Asil, E., Osmanlı Saray Eczacılığı ve Osmanlılar Devrinde Kullanılan Drogların Farmakoloji ve Farmakognozi Yönünden İfade Ettiği Değerler. Doktora Tezi, A.Ü. Ecz. Fak., (1974).

2- Asil, E., Anadolu Selçukluları Devri Tıp ve Eczacılık Kurumu, Doçentlik Tezi (1979).

3- Asil, E., Soner, O., Ankara Eczacı Odan Bülteni, 3 (4), 9-14 (1981).

4- Baylav, N., Eczacılık Tarihi, Yörük Mat. İstanbul (1968).

5- Baytop, A., Farmasötik Botanik, Baha Mat. İstanbul (1977).

6- Baytop, T., Türkiye'nin Tibbi ve Zehirli Bitkileri, İsmail Akgün Mat.İstanbul (1963).

7- Baytop, T., Farmakognoziye Giriş, İsmail Akgün Mat. İstanbul (1966).

8- Bezanger-Beauquesne, L., Pinkas, M., Torek, M., Les Plantes dans la Thérapeutique Moderne, Paris (1975).

9- Bezanger-Beauquesne, L., Garnier, G., Debraux, G., Ressources Médicinales de la Flore Français, 1, 2, Paris (1961).

11- Claus, E.P., Varro, E.T., Brady, L.R., Pharmacognosy, USA (1971).

12- Çelebioğlu, S., Farmakognozi Repetitorium, Çelik Cilt Mat. Istanbul (1963).

13- Demirhan, A., Mısır Çarşısı Drogları, Sermet Mat. İstanbul (1975).

14- Dinçer, F., Türk Folklorunda Veteriner Hekimliği Üzerine Araştırmalar, A.Ü.Basimevi, Ankara (1967).

15- Goldstein, K.S., Sahada Folklor Derleme Metodları. (Çeviren: Uysal, A.E.) Başbakanlık Basımevi, Ankara (1977).

10- Boratav, P.N., 100 Soruda Türk Folkloru, Gerçek Yayınevi, İstanbul (1973).

16- Gunther, R.T., The Greek Herbal of Dioscorides, Hafher Publishing Co., New York (1959). 
17- Güven, K.C., Tıbbi Fomüler, Çelik Cilt Mat.İstanbul (1969).

18- Hamarneh, S.K., Al-Biruni Book on Pharmacy and Materia Medica, Hamdard National Foundation, Pakistan, Karachi (1973).

19- Hüseyin, S., Düstur al-Edviye, Mekteb-i Tıbbiye Mat.İstanbul (1874).

20- Karamanoğlu, K., Farmasötik Botanik, A.Ü.Ecz.Fak. Yayını No: 24, Ankara (1973).

21 - Major, R.H., A History of Medicine, Menasha Press, USA (1954).

22- Margotta, R., An Illustrated History of Medicine, Hamlyn Publishing Group, Verona (1968).

23- Mettler, C.C., History of Medicine, Blakiston Com.Toronto (1947).

24- Öktel, N.M., Farmakoloji I, Güzel Istanbul Mat.Ankara (1964).

25- Öktel, N.M., Farmakoloji II, Güzel İstanbul Mat. Ankara (1965).

26- Özalp, E., Süt ve Mamulleri Teknolojisi, A.Ü.Vet.Fak. Ankara (1979).

27- Perrot, E., Paris, R., Les Plantes Médicinales I, Presses Universitaires, de France (1971).

28- Perrot, E., Paris, R., Les Plantes Médicinales II, Presses Universitaires de France (1971).

29- Sigerist, H.E., A History of Medicine, Oxford Uni. Pr. New York (1961).

30- Şehsuvaroğlu, B.N., Eczacılık Tarihi, Hüsnü Tabiat Mat.İstanbul (1970).

31 - Tanker, M., Yüksek Bitkilerden elde edilen antibiyotikler, İ.Ü. Eczacılık Yıllığı (1963).

32- Tanker, M., Tanker, N., Farmakognozi I, Özışık Mat. Istanbul(1973).

33- Tanker, M., Tanker, N., Farmakognozi II, Reman Mat. İstanbul (1976).

34- Vural, N., Güley, M., Toksikoloji, A.Ü.Basımevi, Ankara (1978).

35- Yakar, N., Renkli Türkiye Bitkileri Atlası, I, II, III, Matbaa Teknisyenleri Basımevi, İstanbul (1964). 